\title{
Studies of the intermediary metabolism in cultured cells of the insect Spodoptera frugiperda using ${ }^{13} \mathrm{C}$ - or ${ }^{15} \mathrm{~N}$-labelled tracers Petra Adam ${ }^{1}$, Markus Gütlich ${ }^{1}$, Hartmut Oschkinat ${ }^{2}$, Adelbert Bacher ${ }^{1}$ and Wolfgang Eisenreich*1
}

Address: ${ }^{1}$ Lehrstuhl für Organische Chemie und Biochemie, Technische Universität München, Lichtenbergstr. 4, D-85747 Garching, Germany and ${ }^{2}$ Forschungsinstitut für molekulare Pharmakologie, Robert-Rössle-Str. 10, D-13125 Berlin, Germany

Email: Petra Adam - petra.adam@gx.novartis.com; Markus Gütlich - guetlich@lrz.tum.de; Hartmut Oschkinat - oschkinat@fmp-berlin.de; Adelbert Bacher - adelbert.bacher@ch.tum.de; Wolfgang Eisenreich* - wolfgang.eisenreich@ch.tum.de

* Corresponding author

Published: 14 November 2005

BMC Biochemistry 2005, 6:24 doi:10.1186/147|-209/-6-24
Received: 25 July 2005

Accepted: 14 November 2005

This article is available from: http://www.biomedcentral.com/147I-209I/6/24

(c) 2005 Adam et al; licensee BioMed Central Ltd.

This is an Open Access article distributed under the terms of the Creative Commons Attribution License (http://creativecommons.org/licenses/by/2.0), which permits unrestricted use, distribution, and reproduction in any medium, provided the original work is properly cited.

\begin{abstract}
Background: Insect cells can serve as host systems for the recombinant expression of eukaryotic proteins. Using this platform, the controlled expression of ${ }^{15} \mathrm{~N} /{ }^{13} \mathrm{C}$ labelled proteins requires the analysis of incorporation paths and rates of isotope-labelled precursors present in the medium into amino acids. For this purpose, Spodoptera frugiperda cells were grown in a complex medium containing $\left[\mathrm{U}^{-13} \mathrm{C}_{6}\right]$ glucose. In a second experiment, cultures of $\mathrm{S}$. frugiperda were grown in the presence of ${ }^{15} \mathrm{~N}$-phenylalanine.
\end{abstract}

Results: Quantitative NMR analysis showed incorporation of the proffered [U-13 $\mathrm{C}_{6}$ ]glucose into the ribose moiety of ribonucleosides $(40-45 \%)$ and into the amino acids, alanine $(41 \%)$, glutamic acid/glutamine (C-4 and C-5, 30\%) and aspartate/asparagine (15\%). Other amino acids and the purine ring of nucleosides were not formed from exogenous glucose in significant amounts (> 5\%). Prior to the incorporation into protein the proffered ${ }^{15} \mathrm{~N}$-phenylalanine lost about $70 \%$ of its label by transamination and the labelled compound was not converted into tyrosine to a significant extent.

Conclusion: Growth of S. frugiperda cells in the presence of $\left[\mathrm{U}_{-}{ }^{3} \mathrm{C}_{6}\right]$ glucose is conducive to the fractional labelling of ribonucleosides, alanine, glutamic acid/glutamine and aspartic acid/asparagine. The isotopolog compositions of the ribonucleosides and of alanine indicate considerable recycling of carbohydrate intermediates in the reductive branch of the pentose phosphate pathway. The incorporation of ${ }^{15} \mathrm{~N}$-labelled amino acids may be hampered by loss of the ${ }^{15} \mathrm{~N}$-label by transamination.

\section{Background}

Cultured insect cells can serve as efficient host systems for the recombinant expression of certain eukaryotic proteins that fail to be expressed in bacterial host systems. Advantageously, insect cells provide eukaryotic type chaperones, permit the expression of long open reading frames, and are not subject to the limitations caused by bacterial codon preferences [1]. Stable isotope labelling is crucial for NMR structure analysis of proteins using multinuclear spectroscopic techniques. Moreover, differential isotope 


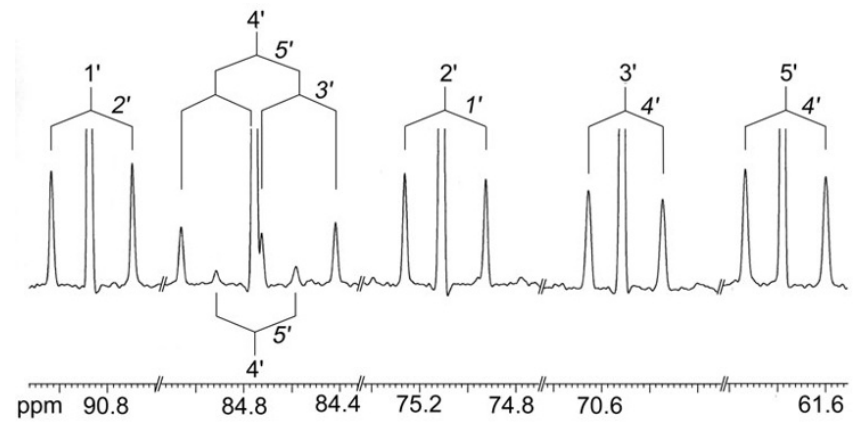

\section{Figure I}

13C NMR signals of cytidine from $S$. frugiperda cells grown with a 1:99 mixture of $\left[\mathrm{U}_{-}{ }^{3} \mathrm{C}_{6}\right]$ glucose and unlabelled glucose added to SF-900 II medium. ${ }^{13} \mathrm{C}$-Coupling patterns are indicated.

labelling can significantly enhance the scope of various other spectroscopic techniques such as EPR, infrared and Raman spectroscopy for the analysis of proteins. Differential ${ }^{15} \mathrm{~N}$ labelling of proteins in Baculovirus-infected insect cells has been achieved via ${ }^{15} \mathrm{~N}$-labelled amino acids present in the growth medium $[2,3]$.

This study was designed to explore in some detail the metabolic network of Spodoptera frugiperda cells under the specific growth conditions for ${ }^{15} \mathrm{~N} /{ }^{13} \mathrm{C}$ labelling. Our data demonstrate that cultured $S$. frugiperda cells grown on commercial culture media rely on exogenous supply rather than on intracellular synthesis of most proteinogenic amino acids, although central metabolic intermediates (i.e., pentose phosphate, oxaloacetate, pyruvate and acetyl-CoA) acquire label from the proffered $\left[\mathrm{U}-{ }^{13} \mathrm{C}_{6}\right]$ lglucose and transamination activity was observed in the experiment with exogenous ${ }^{15} \mathrm{~N}$-phenylalanine.

\section{Results}

In order to assess the utilization of glucose for the biosynthesis of amino acids and ribonucleotides, we cultured $S$. frugiperda cells in a complex culture medium supplemented with a mixture of $\left[\mathrm{U}^{-13} \mathrm{C}_{6}\right.$ ]glucose and unlabelled glucose at a ratio of 1:99. The cells were harvested, and lipids were removed by solvent extraction. Cellular RNA was hydrolysed by alkali treatment, and the resulting ribonucleotides were isolated and dephosphorylated. The resulting nucleosides were further purified by HPLC. The residue obtained after alkali treatment consisted predominantly of protein and was hydrolyzed by hydrochloric acid. Amino acids were isolated chromatographically from the hydrolysate.
${ }^{1} \mathrm{H}$ and ${ }^{13} \mathrm{C}$ NMR spectra were determined for all isolated metabolites. ${ }^{13} \mathrm{C}$ Abundances were determined by quantitative NMR spectroscopy (see Methods). ${ }^{13} \mathrm{C}$ Signals of isotopologs carrying two or more adjacent ${ }^{13} \mathrm{C}$ atoms were characterized by satellite signals arising by ${ }^{13} \mathrm{C}^{13} \mathrm{C}$ couplings. As an example, the ${ }^{13} \mathrm{C}$ signals of the ribose carbon atoms of cytidine showed satellites indicating coupling to one or two adjacent ${ }^{13} \mathrm{C}$ atoms (Fig. 1). More specifically, the signals of carbon atoms 1', 2', 3' and 5' appeared as pseudotriplets where the central lines represent molecules with a single ${ }^{13} \mathrm{C}$ atom, whereas the satellites indicate molecules with blocks of two ${ }^{13} \mathrm{C}$ atoms. The signature of the ribose carbon atom 4' displayed a central line, a doublet and a double-doublet indicating the presence of three different ${ }^{13} \mathrm{C}$-labelled isotopologs, namely $\left[4^{\prime}-{ }^{13} \mathrm{C}_{1}\right]-,\left[4^{\prime}, 5^{\prime}-\right.$ $\left.{ }^{13} \mathrm{C}_{2}\right]-$, and $\left[3^{\prime}, 4^{\prime}, 5^{\prime}-{ }^{13} \mathrm{C}_{3}\right]$ cytidine, respectively.

From the relative fractions of each respective satellite pair in the total ${ }^{13} \mathrm{C}$ NMR signals $\left(\%{ }^{13} \mathrm{C}^{13} \mathrm{C}\right.$ in Table 1$)$ the abundance (in mol\%) of the different isotopologs in the ribose moiety of cytidine (1) was calculated (Fig. 2). Notably, the abundance of multiply ${ }^{13} \mathrm{C}$-substituted molecules can be determined independently from the signal pattern of two or more different carbon atoms. The accuracy of the measurements can therefore be assessed statistically. The standard deviations document the accuracy of the method (Fig. 2).

The isotopolog compositions of the ribose side chains of adenosine (2) and guanosine (3) were closely similar to that of cytidine (1) (cf. Table 1 and Fig. 2). The sugar units of these nucleosides are all derived from the cellular pentose phosphate pool and the close similarity of their labelling patterns as shown by the low standard deviations (Fig. 3) again document the precision of the experimental data. The average labelling pattern revealed the presence of $\left[1,2-{ }^{13} \mathrm{C}_{2}\right]$ - and $\left[3,4,5-{ }^{13} \mathrm{C}_{3}\right]$ ribose moieties at relatively high abundances of 0.41 and $0.42 \mathrm{~mol} \%$, respectively. $\left[4,5-{ }^{13} \mathrm{C}_{2}\right]$ Ribose moieties were present at substantially lower abundance $(0.06 \mathrm{~mol} \%)$. [U-13 $\mathrm{C}_{5}$ ]Ribose moieties and other multiply ${ }^{13} \mathrm{C}$-labelled ribose isotopologs were virtually absent (less than $0.05 \mathrm{~mol} \%$ ). As described in more detail below, it follows that the ribose pool was primarily alimented by the reductive branch of the pentose phosphate pool, whereas the direct pathway via oxidative decarboxylation of the applied $\left[\mathrm{U}^{-13} \mathrm{C}_{6}\right]$ glucose played an almost negligible role. From the molar fraction of ${ }^{13} \mathrm{C}$ labelled glucose in the medium (approximately 1\%) and the molar fractions of multiply ${ }^{13} \mathrm{C}$-labelled isotopologs (see above), a specific incorporation of the proffered [U${ }^{13} \mathrm{C}_{6}$ ]glucose into the ribosyl moiety of nucleosides can be estimated as $40-45 \%$ (Table 2).

The ${ }^{13} \mathrm{C}$ NMR signals of $\mathrm{C}-4$ and $\mathrm{C}-5$ in the pyrimidine ring of cytidine (1) also showed ${ }^{13} \mathrm{C}^{13} \mathrm{C}$ satellites. The 
Table I: Isotopolog compositions of nucleosides from S. frugiperda cells grown with a mixture of [U-I3C6]glucose and natural abundance glucose.

\begin{tabular}{|c|c|c|c|c|c|}
\hline Compound & Position & $\begin{array}{c}{ }^{13} \text { C NMR Chemical } \\
\text { Shift }(\delta, \text { ppm) }\end{array}$ & $\begin{array}{l}\text { Coupling Con- } \\
\text { stants } J_{c c}(\mathrm{~Hz})\end{array}$ & $\%{ }^{13} \mathbf{C a}^{a}$ & $\%^{13} \mathbf{C}^{13} \mathbf{C b}^{b}$ \\
\hline \multirow[t]{9}{*}{ Cytidine (I) } & 2 & 159.7 & & 1.1 & \\
\hline & 4 & 168.4 & $55.5(5)$ & 1.3 & $7.3(5)$ \\
\hline & 5 & 98.9 & $55.3(4)$ & 1.2 & $8.5(4)$ \\
\hline & 6 & 144.4 & & 1.2 & \\
\hline & $I^{\prime}$ & 92.2 & $42.7\left(2^{\prime}\right)$ & 1.6 & 22.1 (2') \\
\hline & $2^{\prime}$ & 76.6 & 42.5 (I') & 1.6 & $22.8\left(I^{\prime}\right)$ \\
\hline & $3^{\prime}$ & 71.9 & $38.7\left(4^{\prime}\right)$ & 1.5 & $25.3\left(4^{\prime}\right)$ \\
\hline & $4^{\prime}$ & 86.4 & $38.7\left(3^{\prime}\right), 42.0\left(5^{\prime}\right)$ & 1.6 & $23.7\left(3^{\prime}, 5^{\prime}\right), 2.8\left(5^{\prime}\right)$ \\
\hline & $5^{\prime}$ & 63.5 & $42.0\left(4^{\prime}\right)$ & 1.5 & $27.4\left(4^{\prime}\right)$ \\
\hline \multirow[t]{10}{*}{ Adenosine (2) } & 2 & 154.7 & & I.I & \\
\hline & 4 & 150.6 & & n.d. & \\
\hline & 5 & 121.3 & & n.d. & \\
\hline & 6 & 157.8 & & 2.7 & \\
\hline & 8 & 142.7 & & 1.1 & \\
\hline & $I^{\prime}$ & 90.4 & $42.7\left(2^{\prime}\right)$ & 1.7 & $23.5\left(2^{\prime}\right)$ \\
\hline & $2^{\prime}$ & 75.8 & 42.5 (I') & 1.8 & 22.8 (I') \\
\hline & $3^{\prime}$ & 72.7 & $38.5\left(4^{\prime}\right)$ & 1.7 & $26.0\left(4^{\prime}\right)$ \\
\hline & $4^{\prime}$ & 87.9 & $41.8\left(5^{\prime}\right), 38.3\left(3^{\prime}\right)$ & 1.6 & $24.6\left(3^{\prime}, 5^{\prime}\right), 2.9\left(5^{\prime}\right)$ \\
\hline & $5^{\prime}$ & 63.6 & $4 I .3\left(4^{\prime}\right)$ & 1.7 & $25.9\left(4^{\prime}\right)$ \\
\hline \multirow{10}{*}{ Guanosine (3) } & 6 & 156.4 & & 1.3 & \\
\hline & 2 & 153.8 & & 1.1 & \\
\hline & 4 & 150.1 & & 1.1 & \\
\hline & 5 & 115.7 & & 1.0 & \\
\hline & 8 & 135.6 & & 1.2 & \\
\hline & $I^{\prime}$ & 86.5 & $42.9\left(2^{\prime}\right)$ & 1.7 & $22.8\left(2^{\prime}\right)$ \\
\hline & $2^{\prime}$ & 73.7 & 42.9 (I') & 1.7 & 22.3 (I') \\
\hline & $3^{\prime}$ & 70.2 & $38.4\left(4^{\prime}\right)$ & 1.7 & $24.1\left(4^{\prime}\right)$ \\
\hline & $4^{\prime}$ & 85.2 & $41.8\left(5^{\prime}\right), 38.0\left(3^{\prime}\right)$ & 1.6 & $26.0\left(3^{\prime}, 5^{\prime}\right), 2.8\left(5^{\prime}\right)$ \\
\hline & $5^{\prime}$ & 61.3 & $42.0\left(4^{\prime}\right)$ & 1.7 & $26.5\left(4^{\prime}\right)$ \\
\hline
\end{tabular}

aabsolute ${ }^{13} \mathrm{C}$ abundance.

brelative fraction of satellite pairs in the global ${ }^{13} \mathrm{C}$ NMR intensity of the index carbon atom. The coupling partners of the index carbon atom are indicated in parentheses.

quantitative analysis revealed the presence of a $\left[4,5-{ }^{13} \mathrm{C}_{2}\right]-$ isotopolog at a molar abundance of $0.1 \mathrm{~mol} \%$ (Fig. 2) which was significantly above the natural abundance level (0.01 mol\%). Moreover, the ${ }^{1} \mathrm{H}$ NMR signal of H-6 (Fig. 4) showed ${ }^{13} \mathrm{C}$ coupling satellites indicating a ${ }^{13} \mathrm{C}$ abundance of $1.2 \mathrm{~mol} \%$ for the $\left[{ }^{6}{ }^{13} \mathrm{C}_{1}\right]$-isotopolog, i.e. 0.1 mol\% excess over the natural ${ }^{13} \mathrm{C}$ abundance of $1.1 \mathrm{~mol} \%$ (see filled circle in Fig. 2). The presence of these isotopologs demonstrates that a fraction of the pyrimidine was biosynthesised de novo from the supplemented ${ }^{13} \mathrm{C}$ labelled glucose via aspartate (see below). The specific incorporation of the proffered ${ }^{13} \mathrm{C}$-glucose into the pyrimidine moiety can be estimated as $10-15 \%$ (Table 2).

The purine ring systems of adenosine and guanosine showed no significantly increased levels of molecular species carrying two or more ${ }^{13} \mathrm{C}$ atoms (Table 1 ). ${ }^{1} \mathrm{H}$ NMR analysis showed no increased ${ }^{13} \mathrm{C}$ abundance for the position 8 methine groups of both nucleosides. Consequently, the data demonstrate that purines were obtained from the culture medium and were not biosynthesised to a significant extent (> 5\%) under the culture conditions (Table 2).

Most amino acids obtained from the protein hydrolysate (i.e. leucine, phenylalanine, tyrosine, lysine, histidine, arginine, serine, threonine, valine, proline, methionine and isoleucine) showed only the low intensity ${ }^{13} \mathrm{C}^{13} \mathrm{C}$ coupling satellites typical for natural abundance compounds. In contrast to the spectra of the amino acids mentioned above, the ${ }^{13} \mathrm{C}$ NMR signals of alanine (4) were characterized by intense satellite signals due to couplings between adjacent ${ }^{13} \mathrm{C}$ atoms. More specifically, the signal for $\mathrm{C}-2$ showed a doublet indicating coupling to ${ }^{13} \mathrm{C}-3$, as well as a double-doublet indicating simultaneous cou- 


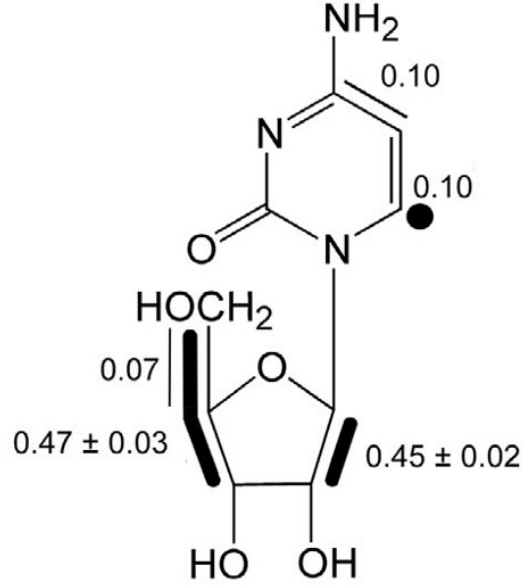

1

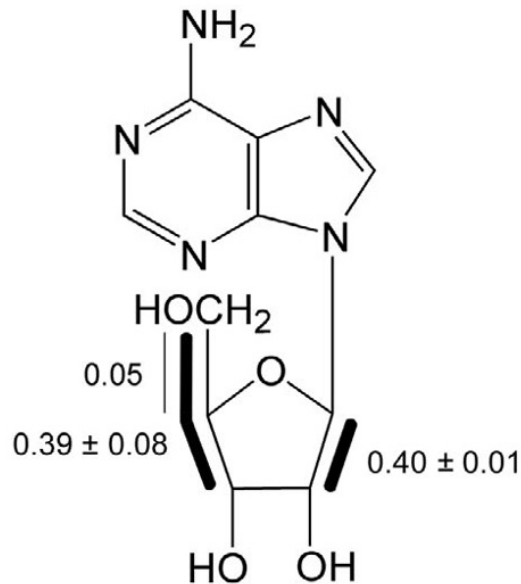

2

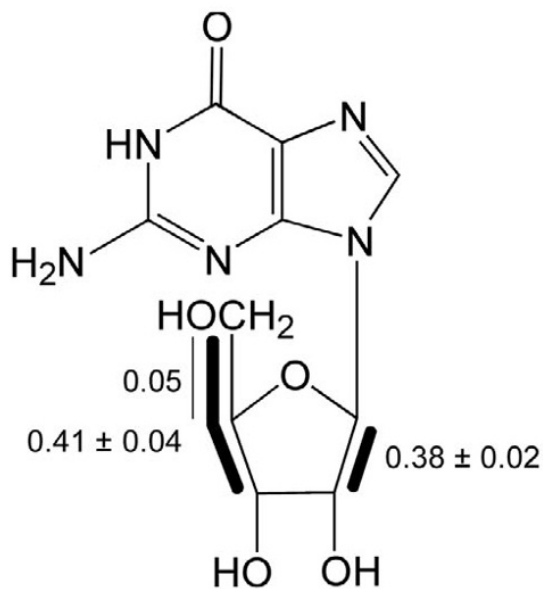

3

\section{Figure 2}

Isotopolog composition of ${ }^{13} \mathrm{C}$-labelled nucleosides from S. frugiperda cells grown with a 1:99 mixture of [U-13 $\left.\mathrm{C}_{6}\right]$ glucose and unlabelled glucose added to SF-900 II medium. The filled dot represents a ${ }^{13} \mathrm{C}_{1}$ isotopolog detected at an abundance well above the natural abundance contribution. Bold lines indicate isotopologs with adjacent ${ }^{13} \mathrm{C}$-labelled carbon atoms that were transferred from the same molecule of $\left[\mathrm{U}_{-}{ }^{3} \mathrm{C}_{6}\right]$ glucose. The numbers give the molar enrichments of the indicated isotopologs.

pling to ${ }^{13} \mathrm{C}-3$ and ${ }^{13} \mathrm{C}-1$. The relative fractions of these satellite pairs in the overall signal intensity of the C-2 signal accounted for 3.8 and $22.2 \%$, respectively, which correspond to an abundance of 0.07 and $0.41 \mathrm{~mol} \%$ for the $\left[2,3-13 \mathrm{C}_{2}\right]$ - and $\left[\mathrm{U}-{ }^{13} \mathrm{C}_{3}\right]$-isotopolog (see also Table 3 and Fig. 5). On this basis, the specific incorporation of the ${ }^{13} \mathrm{C}$ glucose into alanine can be estimated as 45 - 50\% (Table 2).

Significantly enhanced levels of doubly ${ }^{13}$ C-labelled isotopologs were also found in glutamate (5) and aspartate (6) (Fig. 5). [4,5-13 $\left.\mathrm{C}_{2}\right]$ Glutamate had a concentration of $0.30 \mathrm{~mol} \%$ indicating a specific incorporation of approximately $30 \%$. $\left[1,2-{ }^{13} \mathrm{C}_{2}\right]-$ and $\left[3,4-{ }^{13} \mathrm{C}_{2}\right]$ aspartate were found at abundances of 0.13 and 0.14 mol\%, respectively. The abundances of these double-labelled species were closely similar to the abundance of $\left[4,5-{ }^{13} \mathrm{C}_{2}\right]$ cytidine (see above).

A second experiment was designed to investigate the incorporation of a ${ }^{15} \mathrm{~N}$-labelled amino acid from the culture medium by $S$. frugiperda cells. The standard culture medium for SF-9 cells contains numerous amino acids in relatively large amounts [4]. Moreover, the yeast extract added to the medium contains peptides which may become available to the growing cells after proteolysis. The following experiment was therefore performed with a customized amino acid and sugar free medium which was supplemented with amino acids as indicated in Experimental Procedures. In a preliminary study, we monitored the proliferation rate of cells growing with media containing different amounts of phenylalanine; the addition of $100 \mathrm{mg}$ per litre was found to be sufficient for maximum growth activity.

An incorporation experiment was then performed with medium containing $100 \mathrm{mg}$ of $\left[{ }^{15} \mathrm{~N}\right]$ phenylalanine per litre. All other medium components were present in standard amounts (cf. Experimental Procedures). After two passages, the cells were harvested and subjected to acid hydrolysis. Phenylalanine and tyrosine were isolated

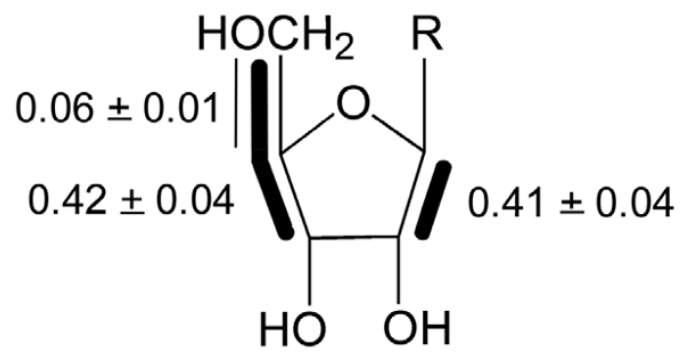

Figure 3

Average isotopolog composition of ${ }^{13} \mathrm{C}$-labelled ribose units in ribonucleosides from $S$. frugiperda cells grown with a 1:99 mixture of $\left[\mathrm{U}_{-}{ }^{13} \mathrm{C}_{6}\right]$ glucose and unlabelled glucose added to SF-900 II medium. Bold lines indicate isotopologs with adjacent ${ }^{13} \mathrm{C}$-labelled carbon atoms that were transferred from the same molecule of $\left[\mathrm{U}_{-}{ }^{3} \mathrm{C}_{6}\right]$ glucose. The numbers give the molar contributions of the indicated isotopologs. 
chromatographically and were analyzed by ${ }^{15} \mathrm{~N}$ and ${ }^{13} \mathrm{C}$ NMR spectrometry, as well as by mass spectrometry.

The ${ }^{15} \mathrm{~N}$ NMR spectrum showed a signal at $35.8 \mathrm{ppm}$ which was assigned to [ $\left.{ }^{15 \mathrm{~N}}\right]$ phenylalanine by internal standardization. The ${ }^{15} \mathrm{~N}$ abundance was determined by ${ }^{13} \mathrm{C}$ NMR spectroscopy. The ${ }^{13} \mathrm{C}$ NMR signals for $\mathrm{C}-2$ and C-3 were accompanied by up-field shifted satellite signals due to ${ }^{15} \mathrm{~N}$ isotope shifts. The sizes of the isotope shifts for C-2 and C-3 (50.9 ppb and $37.6 \mathrm{ppb}$, respectively) as well as the ${ }^{13} \mathrm{C}^{15} \mathrm{~N}$ coupling constant of $3.7 \mathrm{~Hz}\left({ }^{1} \mathrm{~J}_{\mathrm{CN}}\right)$ were in accordance with published values $[5,6]$. The relative fractions of the signal intensities of the up-field shifted satellites in the overall ${ }^{13} \mathrm{C}$ NMR signal intensities of C-2 and C-3 accounted for $25 \pm 2 \%$. This value was confirmed by GC/MS of the N-trifluoroacetyl-n-butylester of phenylalanine [7]. A relative abundance of $30 \pm 8 \%$ was determined for the ${ }^{15} \mathrm{~N}$-labelled fragment $(\mathrm{m} / \mathrm{z}=216)$. Tyrosine isolated from cell protein was not ${ }^{15} \mathrm{~N}$-labelled.

\section{Discussion}

Intermediary metabolism constitutes a complex network with hundreds to thousands of nodes depending on the genetic complexity of the experimental system. The nodes in the central area of the intermediary metabolic network involving the reciprocal transformation of simple carbohydrates, carboxylic and dicarboxylic acids are typically connected by short links. Notably, the sizes and complexity of networks in different organisms can now be compared in some detail on the basis of whole genome sequence data of more than 100 species. The comprehensive quantitative description of such a network requires, in principle, the quantitative assessment of forward and backward reactions mediated by hundreds to thousands of enzymes under intracellular conditions; studies in cell extracts after disruption of cellular integrity can hardly serve as substitute. However, an in vivo approach can be performed with cells or organisms on the basis of perturbation/relaxation analysis of the isotopolog distribution in target metabolites [8-16].

Table 2: Specific incorporation of proffered glucose into metabolites of $S$. frugiperda cells grown in SF-900 II medium.

\begin{tabular}{ll}
\hline Compound & Specific incorporation in\% \\
\hline Nucleosides & \\
Ribose moiety & $40-45$ \\
Pyrimidine base & $10-15$ \\
Purine base & $<5$ \\
Amino acids & \\
Alanine & $45-50$ \\
Glutamate/Glutamine (C-4/C-5) & 30 \\
Aspartate/Asparagine & $10-15$ \\
Others & $<5$ \\
\end{tabular}

This approach can be briefly summarized as follows. Naturally occurring organic matter is a highly complex mixture of isotopologs comprising all stable isotopes of hydrogen, carbon and nitrogen. The natural abundance of ${ }^{13} \mathrm{C}$ is about $1.1 \%$. In the quasi-equilibrium mixture of natural organic material of low molecular weight, the isotopologs carrying more than one ${ }^{13} \mathrm{C}$ atom are of low abundance; as an example, the approximate natural abundances of some ${ }^{13} \mathrm{C}$-isotopologs of ribose are shown in Table 4.

The introduction of a ${ }^{13} \mathrm{C}$-labelled compound into any biological system constitutes a local perturbation of the quasi-equilibrium state of isotopolog distribution in the respective metabolic network. Such a perturbation can spread in the network by way of enzymatic interconversion. The comprehensive analysis of the network-wide metabolic relaxation processes resulting from such an initial perturbation requires, in principle, the analysis of isotopolog compositions at virtually every node of the network at various times after the onset of the perturbation. In metabolic networks of typical prokaryotes and

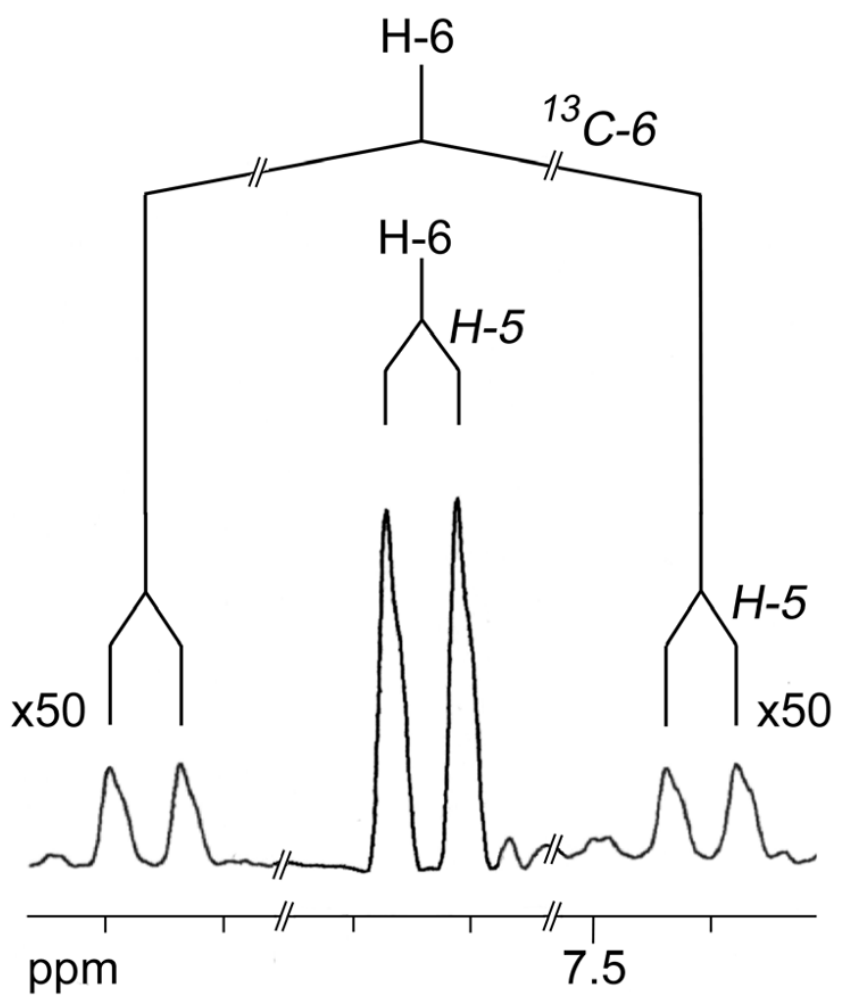

Figure 4

IH NMR signal of $\mathrm{H}-6$ of cytidine from $\mathrm{S}$. frugiperda cells grown with a 1:99 mixture of $\left[\mathrm{U}_{-}{ }^{13} \mathrm{C}_{6}\right]$ glucose and unlabelled glucose added to SF-900 II medium. The amplitude of the satellites is 50 -fold enlarged by comparison with the central signal. The coupling pattern is indicated. 
Table 3: Isotopolog compositions of amino acids from S. frugiperda cells grown in a mixture of $\left[\mathrm{U}^{13} \mathrm{C}_{6}\right]$ glucose and natural abundance glucose.

\begin{tabular}{|c|c|c|c|c|c|}
\hline Compound & Position & $\begin{array}{c}{ }^{13} \text { Chemical Shift } \\
(\delta, \text { ppm })\end{array}$ & $\begin{array}{l}\text { Coupling Con- } \\
\text { stants } J_{C c}(\mathrm{~Hz})\end{array}$ & $\%^{13} \mathrm{Ca}^{\mathrm{a}}$ & ${ }^{13} \mathrm{C}^{13} \mathrm{C}^{b}$ \\
\hline \multirow[t]{3}{*}{ Alanine (4) } & 1 & 175.7 & n.d. & n.d. & n.d. \\
\hline & 2 & 51.4 & $59.6(1), 34.9(3)$ & 1.8 & $3.8(3), 22.2(I, 3)$ \\
\hline & 3 & 18.4 & $35.1(2)$ & 1.7 & $26.5(2)$ \\
\hline \multirow[t]{4}{*}{ Aspartate (5) } & I & 182.9 & n.d. & n.d. & n.d. \\
\hline & 2 & 61.3 & $60.4(1)$ & 1.8 & $7.4(I)$ \\
\hline & 3 & 45.9 & $55.3(4)$ & 1.9 & $7.2(4)$ \\
\hline & 4 & 185.1 & $55.7(3)$ & 1.8 & $7.6(3)$ \\
\hline \multirow[t]{5}{*}{ Glutamate (6) } & I & 176.1 & & 1.3 & \\
\hline & 2 & 56.2 & & 1.0 & \\
\hline & 3 & 27.9 & & I.I & \\
\hline & 4 & 32.5 & $55.1(5)$ & 1.8 & I7.| (5) \\
\hline & 5 & 179.6 & $55.1(4)$ & 1.7 & $17.2(4)$ \\
\hline
\end{tabular}

aabsolute ${ }^{13} \mathrm{C}$ abundance.

brelative fraction of satellite pairs in the global ${ }^{13} \mathrm{C}$ NMR intensity of the index carbon atom. The coupling partners of the index carbon atom are indicated in parentheses.

n.d., not determined due to poor signal quality.

eukaryotes comprising hundreds to thousands of nodes, this is a relatively tall order. However, the task can be simplified quite considerably in light of two considerations. (i) Since metabolic networks are highly crosslinked via enzyme-catalyzed reactions, it is sufficient to measure the isotopolog distribution at a relatively small number of nodes. The isotopolog composition at numerous adjacent nodes can then be estimated on the basis of certain wellknown enzyme catalyzed reactions. (ii) Following a perturbation of the isotopolog equilibrium, the relaxation process is typically not conducive to a true equilibrium state, since anabolic processes lead to a quasisteady state; only catabolic processes are conducive to actual reequilibration.
In practical terms, primary metabolites such as amino acids and nucleic acid constituents are biosynthetically derived from pools of small molecules by anabolic reactions. These primary metabolites are assembled from simple carbohydrates, carboxylic and dicarboxylic acids which are present in low amounts and are at the same time subject to rapid turnover. On the other hand, the products of primary metabolism (amino acids, nucleic acid components) become embedded into polymers (proteins, nucleic acids) where their turnover rate is relatively low. Thus, they reflect the isotopolog distribution of the central intermediary pools (carbohydrates, carboxylic acids) at the time of their formation. Based on these considerations, the transient label distribution in the central<smiles></smiles>

\section{Figure 5}

Isotopolog composition of ${ }^{13} \mathrm{C}$-labelled amino acids from S. frugiperda cells grown with a I:99 mixture of [U-13 $\mathrm{C}_{6}$ ]glucose and unlabelled glucose added to SF-900 II medium. Bold lines indicate isotopologs with adjacent ${ }^{13} \mathrm{C}$-labelled carbon atoms that were transferred from the same molecule of $\left[\mathrm{U}_{-}{ }^{13} \mathrm{C}_{6}\right]$ glucose. The numbers give the molar contributions of the indicated isotopologs. 
Table 4: Approximate natural abundance of selected ribose isotopologs carrying ${ }^{13} \mathrm{C}$.

\begin{tabular}{ll}
\hline Isotopolog & Abundance [mol\%] \\
\hline$\left[1-{ }^{13} C_{1}\right]$ & 1.1 \\
{$\left[2-{ }^{13} C_{1}\right]$} & 1.1 \\
{$\left[3-{ }^{13} C_{1}\right]$} & 1.1 \\
{$\left[1,2-{ }^{13} C_{2}\right]$} & 0.012 \\
{$\left[4,5-{ }^{13} C_{2}\right]$} & 0.012 \\
{$\left[1,2,3-13 C_{3}\right]$} & 0.00013 \\
{$\left[3,4,5-13 C_{3}\right]$} & 0.00013 \\
{$\left[U-{ }^{3} C_{5}\right]$} & 0.000000018
\end{tabular}

metabolite pools can be easily gleaned from analysis of the monomeric building blocks of proteins and nucleic acids (for review, see [13]).

The formation of pentose derviatives from $\left[\mathrm{U}-{ }^{13} \mathrm{C}_{6}\right]$ glucose by oxidative decarboxylation via the oxidative branch of the pentose phosphate pathway, if active to a significant extent, should have afforded $\left[\mathrm{U}^{13} \mathrm{C}_{5}\right]$ ribose phosphate. The virtual absence of that species in the ribonucleosides analyzed indicates that other metabolic processes (i.e. glycolytic cycling prior to any oxidative decarboxylation of glucose) must have played a crucial role. The observed isotopolog pattern can be best explained by cooperation of the reductive branch of the pentose phosphate cycle with glycolysis and regeneration of glucose from triose pool intermediates. Passage through the reductive branch of the pentose phosphate pathway results in breaking of the bond between C-3 and $\mathrm{C}-4$ of glucose. The same is true for glycolysis. Both pathways afford $\left[\mathrm{U}^{1}{ }^{13} \mathrm{C}_{3}\right]$ lglyceraldehyde 3 -phosphate from carbon atoms 4 through 6 of the proffered $\left[\mathrm{U}-{ }^{13} \mathrm{C}_{6}\right]$ lglucose. The utilization of that intermediate by transketolase affords a $\left[3,4,5-{ }^{13} \mathrm{C}_{3}\right]$ pentulose. On the other hand, grafting of a $\left[{ }^{13} \mathrm{C}_{2}\right]$-fragment derived from $\left[\mathrm{U}^{13} \mathrm{C}_{6}\right]$ glucose to an unlabelled glyceraldehyde phosphate moiety affords $\left[1,2-{ }^{13} \mathrm{C}_{2}\right]$ pentulose phosphate isotopologs (species 6 in Fig. 6A).

Glucogenesis using $\left[{ }^{13} \mathrm{C}_{3}\right]$ triose phosphates and unlabelled triose phosphates in excess (from the unlabelled glucose fraction) is conducive to the formation of $[1,2,3$ $\left.{ }^{13} \mathrm{C}_{3}\right]-$ and $\left[4,5,6-{ }^{13} \mathrm{C}_{3}\right]$ hexose phosphates. Oxidative decarboxylation of these species also affords $\left[1,2-13 \mathrm{C}_{2}\right]-$ and $\left[3,4,5-{ }^{13} \mathrm{C}_{3}\right]$ pentose phosphates, respectively (Fig. $6 B)$.

The formation of minor amounts of $\left[4,5-{ }^{13} \mathrm{C}_{2}\right]$ pentoses can be explained by the transfer of a $\left[{ }^{13} \mathrm{C}_{2}\right]$ fragment from a $\left[1,2-{ }^{13} \mathrm{C}_{2}\right]$ pentulose phosphate (species 6 ) to unlabelled erythrose phosphate by the action of transketolase. The resulting $\left[1,2-{ }^{13} \mathrm{C}_{2}\right]$ fructose phosphate (species 7) can then be converted to $\left[2,3-{ }^{13} \mathrm{C}_{2}\right]$ triose phosphate which affords $\left[4,5-{ }^{13} \mathrm{C}_{2}\right]$ pentose phosphate by recycling in the pentose phosphate cycle (Fig. 6A). The labelling patterns of the carbohydrate moieties indicate that ${ }^{13} \mathrm{C}$-label is transferred efficiently to the triose phosphate pool by the joint action of glycolysis and the pentose phosphate cycle.

On the basis of the pyruvate/alanine transamination reaction, the labelling pattern of alanine can be taken as a reference for the labelling pattern of pyruvate. The isotopolog composition of alanine (4) was in perfect agreement with the labelling pattern of the three carbon moiety comprising C-3, C-4 and C-5 in the ribose unit of ribonucleosides (cf. Figs. 3 and 5). As discussed above, the latter moiety is biosynthetically equivalent to the triose phosphate pool and, on this basis, the isotopolog compositions of triose phosphate and pyruvate are apparently identical. It can be concluded that pyruvate is predominantly or exclusively biosynthesized from the triose phosphate pool via phosphoenolpyruvate and that alternative routes leading to pyruvate (e.g., via decarboxylation of oxaloacetate) do not contribute significantly to the de novo pyruvate synthesis under the experimental settings.

The presence of $\left[4,5-{ }^{13} \mathrm{C}_{2}\right]$ glutamate indicates its formation from $\left[4,5-{ }^{13} \mathrm{C}_{2}\right] 2$-ketoglutarate (species 8 ) which is assembled from oxaloacetate and $\left[1,2-{ }^{13} \mathrm{C}_{2}\right]$ acetyl-CoA via the citrate cycle (Fig. 6C). Following the reactions of the citrate cycle, $\left[4,5-{ }^{13} \mathrm{C}_{2}\right] 2$-ketoglutarate is converted into a mixture of $\left[1,2-{ }^{13} \mathrm{C}_{2}\right]-$ and $\left[3,4-{ }^{13} \mathrm{C}_{2}\right]$ oxaloacetate (species 9) via the symmetric intermediates succinate and fumarate. Transamination of these oxaloacetate species yields the detected aspartate isotopologs. Reaction of $[3,4-$ ${ }^{13} \mathrm{C}_{2}$ loxaloacetate with acetyl-CoA should have afforded $\left[1,2-{ }^{13} \mathrm{C}_{2}\right] 2$-ketoglutarate via the citrate cycle. Notably, this species is not reflected in the labelling pattern of analyzed glutamate. One possible explanation for this finding is the existence of two compartmented oxaloacetate and/ or 2-ketoglutarate pools (i) providing substrates for the citrate cycle and (ii) providing substrates for transamination. Further experiments are necessary to clarify this hypothesis.

By comparison with alanine, the label concentration in the acidic amino acids derived from citrate cycle intermediates is significantly lower. This could be due to the incorporation of exogenously supplied glutamate and aspartate into protein. This is not surprising since the culture medium used contained relatively large amounts of asparagine, aspartate, glutamate and glutamine.

The virtual absence of label in many amino acids, with the exception of alanine, glutamate and aspartate, indicates that the de novo synthesis under the experimental conditions was limited to those amino acids which can be obtained by single step transamination reactions from 
<smiles></smiles>

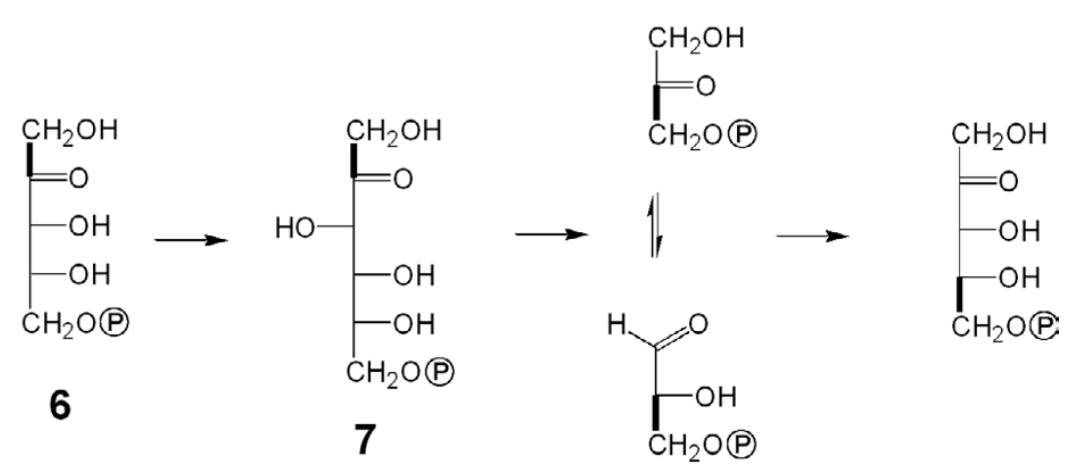

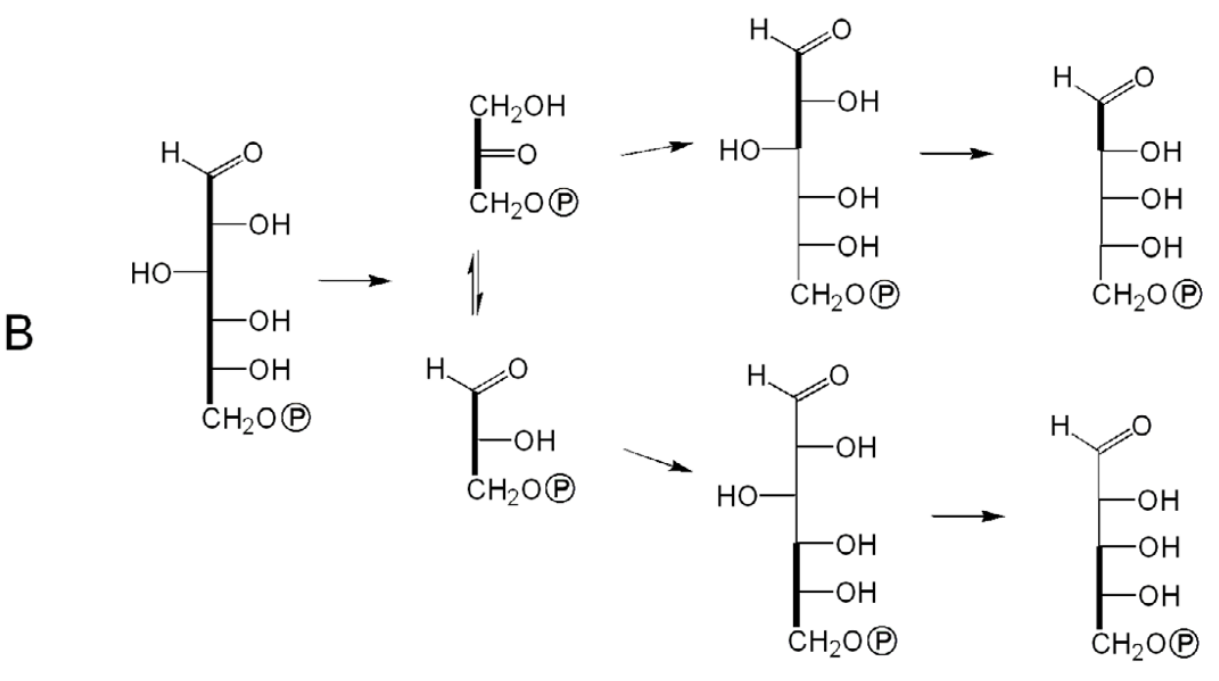<smiles>CCC(C(=O)[O-])C(=O)C([NH3+])C(C(=O)[O-])C(=O)C(=O)[O-]</smiles>

\section{Figure 6}

Metabolic processes involved in pentose/pentulose formation from [ $\left.\mathrm{U}_{-}{ }^{13} \mathrm{C}_{6}\right]$ glucose in a large excess of unlabelled glucose $(\mathrm{A})$, via the pentose phosphate cycle and (B), via glycolytic cycling followed by the pentose phosphate cycle. (C), Metabolic processes involved in the formation of the detected aspartate isotopologs. Bold lines connect ${ }^{13} \mathrm{C}$-atoms in a given molecular species. 
keto acids which are abundantly present in intermediary metabolism (pyruvate, oxaloacetate and ketoglutarate) (Fig. 7). Under the experimental conditions, remodelling of carbon skeletons for the purpose of amino biosynthesis proceeded at a very low level, if at all.

Recently, the incorporation of ${ }^{13} \mathrm{C}$-glucose into recombinant Abl kinase expressed in Baculovirus-infected insect cells was studied by Strauss et al. [17]. The incorporation rates of glucose into amino acids (i.e., only into alanine, glutamate/glutamine and aspartate/asparagine) were similar to the data presented in our study.

In line with the finding that transamination is the only significant activity with regard to the biosynthesis of aliphatic amino acids, the experiment with $\left[{ }^{15} \mathrm{~N}_{1}\right]$ phenylalanine shows that transamination occurs on a relatively high level. Although the proffered $\left[{ }^{15} \mathrm{~N}_{1}\right]$ isotopolog was apparently the only source of phenylalanine, the sample isolated from cell protein retained only about $30 \%$ of ${ }^{15} \mathrm{~N}$ label. This is in notable contrast to an earlier study, where incorporation rates of $>90 \%$ have been reported for exogenous ${ }^{15} \mathrm{~N}$-phenylalanine into human $\mathrm{Abl}$ kinase expressed in Baculovirus-infected insect cells $[3,17]$. The reasons for this apparent discrapency might be (i) the difference of the protein/protein fraction analyzed by NMR spectroscopy in the two studies, (ii) different concentrations of the supplied ${ }^{15} \mathrm{~N}$-phenylalanine, and/or (iii) the difference of the experimental setup with the culture systems.

More specifically, growing cells of the insect were studied in our study. All cellular proteins were then hydrolyzed and amino acids were subjected to NMR analysis. In the studies of Strauss et al. $[3,17]$ insect cells were transfected with Baculovirus and recombinant protein (i.e., c-Abl kinase) was analyzed. The concentrations of exogenous ${ }^{15} \mathrm{~N}$-phenylalanine were 10 -fold different in the two studies and it cannot be excluded that minor amounts of unlabelled phenylalanine were still present in the culture medium (i.e., "SF-900 II medium without amino acids and without sugar", Gibco) used in our study.

Isolated tyrosine did not contain detectable amounts of ${ }^{15} \mathrm{~N}$. This suggests that hydroxylation of phenylalanine does not take place to a significant extent, although phenylalanine hydroxylase is known to be present in insects [18-20].

\section{Conclusion}

Our findings are relevant for the design of protein labelling with recombinant $S$. frugiperda cells. The following aspects need to be considered. (i) The standardized media contain amino acids in relatively large excess over the real metabolic needs of the cells. Obviously, the concentration of isotope labelled amino acids in the medium should be optimized (i.e., reduced to an appropriate level).

(ii) Differential ${ }^{13} \mathrm{C} /{ }^{15} \mathrm{~N}$ labelling of most amino acids (i.e. leucine, phenylalanine, tyrosine, lysine, histidine, arginine, serine, threonine, valine, proline, methionine and isoleucine) can be achieved via the respective labelled amino acids present in the growth medium (see also, $[2,3,17])$. However, labelling with ${ }^{15} \mathrm{~N}$ could be hampered by the relatively high transamination activity in the cells (cf. also [21]). Hence, the carbon skeleton of specific $\left[{ }^{13} \mathrm{C},{ }^{15} \mathrm{~N}\right]$-labelled amino acids would be incorporated intact, but the nitrogen label would be subject to extensive dilution by nitrogen from other, non-labelled amino acids. It may be possible to counteract this isotope loss by the addition of a mixture of $\left[{ }^{15} \mathrm{~N}\right]$-amino acids (e.g., glutamine and asparagine).

(iii) Fractional ${ }^{13} \mathrm{C}$ labelled proteins comprising [U${ }^{13} \mathrm{C}_{3}$ ]alanine, $\left[4,5-{ }^{13} \mathrm{C}_{2}\right]$ glutamate, $\left[1,2-{ }^{13} \mathrm{C}_{2}\right]-$ and $[3,4-$ ${ }^{13} \mathrm{C}_{2}$ ]aspartate can be obtained by addition of [U${ }^{13} \mathrm{C}_{6}$ lglucose to the growth medium.

\section{Methods \\ Materials}

$\left[\mathrm{U}-{ }^{13} \mathrm{C}_{6}\right]$ Glucose and $\left[{ }^{15} \mathrm{~N}\right]$ phenylalanine were obtained from Isotec, Miamisburg, Ohio, USA. SF-900 II medium was obtained from Gibco, Karlsruhe, Germany.

\section{Cell culture}

SF-9 cells were grown in SF-900 II medium [4]. The cells were kept at a density of $2 \times 10^{5}$ to $2 \times 10^{6}$ cells $/ \mathrm{ml}$ at $28^{\circ} \mathrm{C}$ in spinner flasks. Expansion cultures were performed in spinner flasks at $28^{\circ} \mathrm{C}$ and $80 \mathrm{rpm}$ or in a shaking flask at $28^{\circ} \mathrm{C}$ and $60 \mathrm{rpm}$. In order to study the metabolic utilization of glucose, the cells were grown in SF-900 II medium supplemented with $\left[\mathrm{U}^{-13} \mathrm{C}_{6}\right.$ ]glucose and unlabelled glucose at a ratio of 1:99 (w/w) for two passages.

In order to study the metabolic utilization of exogenous phenylalanine, SF-9 cells were grown in "SF-900 II medium without amino acids and without sugar" (Gibco) with the following supplements: D-glucose $(10 \mathrm{~g} / \mathrm{l}), \mathrm{D}$ maltose $(1 \mathrm{~g} / \mathrm{l})$, D-sucrose $(1.65 \mathrm{~g} / \mathrm{l}), \beta$-alanine $(300 \mathrm{mg} /$ l), L-arginine $(800 \mathrm{mg} / \mathrm{l})$, L-asparagine $(1.3 \mathrm{~g} / \mathrm{l})$, L-aspartate $(1.3 \mathrm{~g} / \mathrm{l}), \mathrm{L}$-cystin, sodium salt $(150 \mathrm{mg} / \mathrm{l}), \mathrm{L}$-glutamate $(1.5 \mathrm{~g} / \mathrm{l})$, L-glutamine $(2 \mathrm{~g} / \mathrm{l})$, glycine $(200 \mathrm{mg} / \mathrm{l})$, Lhistidine $(200 \mathrm{mg} / \mathrm{l})$, 2-hydroxyproline $(700 \mathrm{mg} / \mathrm{l})$, L-isoleucine $(750 \mathrm{mg} / \mathrm{l})$, L-leucine $(250 \mathrm{mg} / \mathrm{l})$, L-lysine hydrochloride $(700 \mathrm{mg} / \mathrm{l})$, L-methionine $(1 \mathrm{~g} / \mathrm{l}),{ }^{15} \mathrm{~N}-\mathrm{L}-$ phenylalanine $(100 \mathrm{mg} / \mathrm{l})$, L-proline $(500 \mathrm{mg} / \mathrm{l})$, DL-serine $(400 \mathrm{mg} / \mathrm{l})$, L-threonine $(200 \mathrm{mg} / \mathrm{l})$, L-tryptophan 


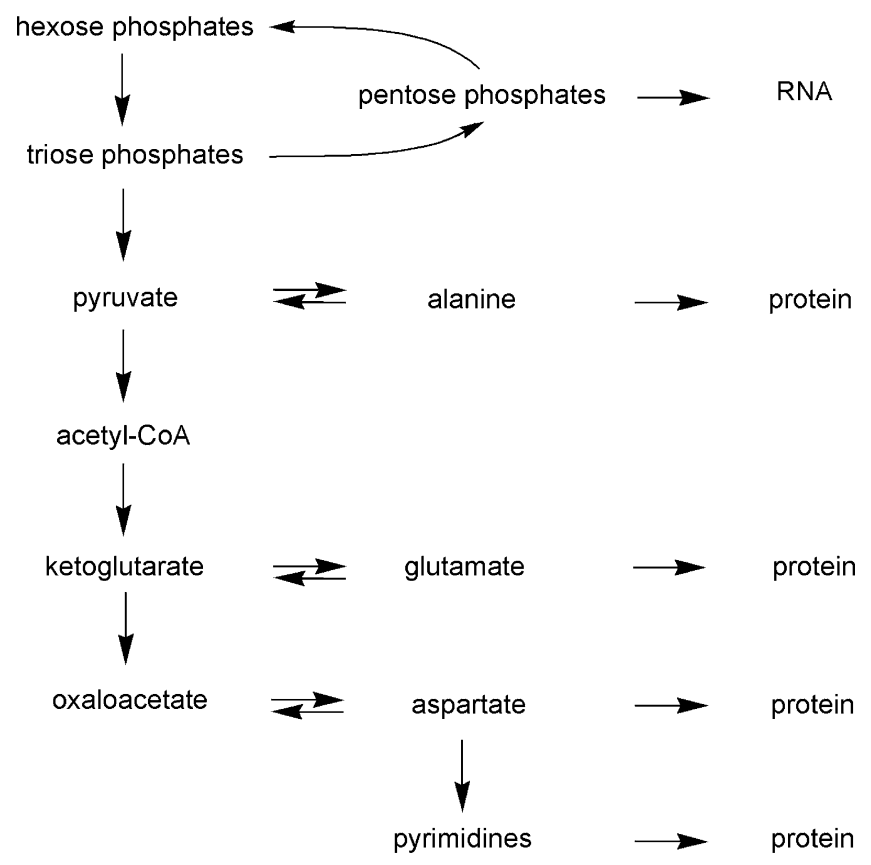

Figure 7

Metabolic network of S. frugiperda cells grown in SF-900 II medium.

(100 mg/l), L-tyrosine (disodium salt dihydrate) (360 $\mathrm{mg} / \mathrm{l})$, and L-valine $(500 \mathrm{mg} / \mathrm{l})$.

\section{Isolation of amino acids and ribonucleosides}

S. frugiperda cells were harvested, washed with saline, and lyophilized. The dry powder ( $3.4 \mathrm{~g}$ ) was extracted with 42 $\mathrm{ml}$ of a methylene chloride/methanol/water mixture (1.1:1:1.1, v/v), as described [22]. The residue was suspended in $14 \mathrm{ml}$ of $1 \mathrm{M} \mathrm{NaOH}$. The mixture was kept at room temperature overnight and was than centrifuged. Nucleotides were isolated from the supernatant as described earlier [23]. Treatment with alkaline phosphatase afforded ribonucleosides which were purified as described earlier [23]. The pellet was hydrolysed by treatment with azeotropic hydrochloric acid for $24 \mathrm{~h}$, and amino acids were isolated chromatographically as described [23]. It should be noted that glutamine and asparagine are converted into glutamate and aspartate, respectively, under the acidic conditions of the hydrolysis. Therefore, analysed glutamic acid and aspartic acid also reflect the contributions of glutamine and asparagine, respectively.

\section{Derivatization of amino acids}

An aliquot of the hydrolysate was lyophilized and dissolved in $200 \mu \mathrm{l}$ of $\mathrm{HCl}$ in n-butanol. The solution was incubated at $100^{\circ} \mathrm{C}$ for $1 \mathrm{~h}$. Butanol was removed under a stream of nitrogen. The residue was incubated with $50 \mu \mathrm{l}$ of trifluoroacetic acid anhydride at room temperature. The mixture was evaporated to dryness at $80^{\circ} \mathrm{C}$. The residue was dissolved in $500 \mu \mathrm{l}$ of ethyl acetate. An aliquot was analyzed by gas chromatography/mass spectrometry (column: DB5-MS, J+W scientific, CA, USA; start temper-

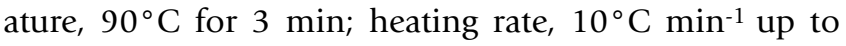
$280^{\circ} \mathrm{C} ; 8 \mathrm{~min}$ at $280^{\circ} \mathrm{C}$ ).

\section{NMR spectroscopy}

Guanosine was dissolved in $0.5 \mathrm{ml}$ of $\mathrm{DMSO}^{-} \mathrm{D}_{6}$, adenosine and cytidine were dissolved in $0.5 \mathrm{ml}$ of $\mathrm{D}_{2} \mathrm{O}$, respectively, and amino acids were dissolved in $0.5 \mathrm{ml}$ of $\mathrm{D}_{2} \mathrm{O}$ / DCl. ${ }^{1} \mathrm{H},{ }^{13} \mathrm{C}$, and ${ }^{15} \mathrm{~N}$ NMR spectra were acquired with a DRX 500 spectrometer from Bruker Instruments, Karlsruhe, at transmitter frequencies of 500.13, 125.76, and $50.7 \mathrm{MHz}$, respectively. The data were processed with standard Bruker software (XWINNMR 3.0). Composite pulse decoupling was used for ${ }^{13} \mathrm{C}$ NMR measurements. No ${ }^{1} \mathrm{H}$ decoupling was applied for ${ }^{15} \mathrm{~N}$ NMR measurements. All spectra were recorded using a flip angle of $30^{\circ}$ and a relaxation delay of $2.0 \mathrm{~s}$. Quadrature detection and quadrature phase cycling were applied in all NMR measurements. The resulting free induction decays were processed by zero filling and multiplication with a Gaussian window function (lb, -1; gb, 0.1). 3-(Trimethylsilyl)-1propanesulfonate served as an external standard for ${ }^{1} \mathrm{H}$ and ${ }^{13} \mathrm{C}$ NMR measurements. ${ }^{15} \mathrm{~N}$ Chemical shifts are reported relative to the ${ }^{15} \mathrm{~N}$ NMR signal of N-5 of [U${ }^{15} \mathrm{~N}_{4}$ ]6,7-dimethyl-8-ribityllumazine at $327.0 \mathrm{ppm} .{ }^{1} \mathrm{H}$ and ${ }^{13} \mathrm{C}$ NMR signal assignments were taken from [23].

\section{Assessment of isotopolog composition}

The isotopolog compositions of nucleosides and amino acids were determined by quantitative NMR spectroscopy (Tables 1 and 3) [24]. Relative ${ }^{13} \mathrm{C}$ abundances were obtained from signal intensities in one-dimensional ${ }^{13} \mathrm{C}$ NMR spectra. Specifically, the signal integrals $\left(\mathrm{I}^{*}\right)$ were determined for each ${ }^{13} \mathrm{C}$ NMR signal of the metabolite under study. Using the same experimental settings, the signal integrals $\left(\mathrm{I}_{\text {ref }}\right)$ of the same compound at natural ${ }^{13} \mathrm{C}$ abundance were determined. The ratios of the signal integrals of each respective carbon atom $\left(\mathrm{I}^{*} / \mathrm{I}_{\text {ref }}\right)$ were then calculated. Absolute ${ }^{13} \mathrm{C}$ abundances were determined for certain carbon positions from the ${ }^{13} \mathrm{C}$ coupling satellites in the ${ }^{1} \mathrm{H}$ NMR spectra (for an example, see Fig. 4). Relative ${ }^{13} \mathrm{C}$ abundances $\left(\mathrm{I}^{*} / \mathrm{I}_{\mathrm{ref}}\right)$ were then referenced to the absolute enrichments.

In NMR spectra of multiply labelled samples displaying ${ }^{13} \mathrm{C}^{13} \mathrm{C}$ coupling (for an example, cf. Fig. 1), each satellite signal in the ${ }^{13} \mathrm{C}$ NMR spectra was integrated separately. The relative fraction of each respective satellite pair in the total ${ }^{13} \mathrm{C}$ NMR signal integral of a given carbon atom was calculated $\left(\%{ }^{13} \mathrm{C}^{13} \mathrm{C}\right.$ in Tables 1 and 3$)$. The relative fractions of satellite pairs were then referenced to the overall 
${ }^{13} \mathrm{C}$ abundance of a respective carbon atom which was determined as described above. This resulted in molar contributions (mol\%) for each respective isotopolog.

\section{Authors' contributions}

PA isolated the metabolites, MG grew the cells, $\mathrm{HO}$ and WE were responsible for the NMR analysis, WE and $A B$ drafted the manuscript.

\section{Acknowledgements}

This work was supported by grants from the Deutsche Forschungsgemeinschaft, the Fonds der Chemischen Industrie and the Hans Fischer Gesellschaft. We thank Fritz Wendling, Angela Grygier and Angelika Werner for expert help with the preparation of the manuscript.

\section{References}

I. Luckow VA, Summers MD: High level expression of nonfused foreign genes with Autographa californica nuclear polyhedrosis virus expression vectors. Virology 1989, I70:31-39.

2. Brüggert M, Rehm T, Shanker S, Georgescu J, Holak TA: A novel medium for expression of proteins selectively labeled with ${ }^{15} \mathrm{~N}$-amino acids in Spodoptera frugiperda (Sf9) insect cells. J Biomol NMR 2003, 25:335-348.

3. Strauss A, Bitsch F, Cutting B, Fendrich G, Graff P, Liebetanz J, Zurinin $M$, Jahnke W: Amino-acid-type selective isotope labeling of proteins expressed in Baculovirus-infected insect cells useful for NMR studies. J Biomol NMR 2003, 26:367-372.

4. Weiss SA, Godwin GP, Gorfien SF, Whitford WG: Serum-free media. Bioprocess Technology 1993, I7:179-194.

5. Blomberg F, Maurer W, Rüterjans H: Nitrogen-I5 nuclear magnetic resonance investigations on amino acids. Proc Natl Acad Sci USA 1976, 73: | 409-1413.

6. Rabenstein DL, Mariappan SVS: Determination of ${ }^{15} \mathbf{N}$ isotope effects on the acid-base equilibria of amino groups in amino acids by carbon-1 3 NMR. J Org Chem 1993, 58:4487-4489.

7. Leimer KR, Rice RH, Gehrke CW: Complete mass spectra of $\mathbf{N}$ trifluoroacetyl-n-butyl esters of amino acids. I Chromatogr 1977, | 41:|2|-| 44.

8. Eisenreich W, Strauß G, Werz U, Bacher A, Fuchs G: Retrobiosynthetic analysis of carbon fixation in the phototrophic eubacterium Chloroflexus aurantiacus. Eur J Biochem 1993 215:619-632.

9. Szyperski T: Biosynthetically directed fractional ${ }^{13} \mathrm{C}$-labeling of proteinogenic amino acids. An efficient analytical tool to investigate intermediary metabolism. Eur J Biochem 1995, 232:433-438.

10. Schmidt K, Marx A, deGraaf AA, Wiechert W, Sahm H, Nielsen J, Villadsen $\mathrm{J}:{ }^{13} \mathrm{C}$ tracer experiments and metabolite balancing for metabolic flux analysis: comparing two approaches. Biotechnol Bioeng 1998, 58:254-257.

II. Fiaux J, Andersson CJY, Holmberg N, Bülow L, Kallio PT, Szyperski T, Bailey JE, Wüthrich K: ${ }^{13} \mathrm{C}$ NMR flux ratio analysis of Escherichio coli central carbon metabolism in microaerobic bioprocesses. I Am Chem Soc 1999, I 2 I: 1 407-1408.

12. Park SM, Klapa MI, Sinskey AJ, Stephanopoulos G: Metabolite and isotopomer balancing in the analysis of metabolic cycles: II. Applications. Biotechnol Bioeng 1999, 62:392-40I.

13. Bacher A, Rieder C, Eichinger D, Arigoni D, Fuchs G, Eisenreich W: Elucidation of biosynthetic pathways and metabolic flux patterns via retrobiosynthetic NMR analysis. FEMS Microbiol Rev $1999,22: 567-598$.

14. Kruger NJ, Ratcliffe RG, Roscher A: Quantitative approaches for analysing fluxes through plant metabolic networks using NMR and stable isotope labelling. Phytochem Rev 2003, 2:17-30.

15. Glawischnig E, Gierl A, Tomas A, Bacher A, Eisenreich W: Starch biosynthesis and intermediary metabolism in maize kernels. Quantitative analysis of metabolite flux by NMR. Plant Physiol 2003, 130: 1717-1727.

16. Eisenreich W, Ettenhuber C, Laupitz R, Theus C, Bacher A: Isotopolog perturbation techniques for metabolic networks.
Metabolic recycling of nutritional glucose in Drosophila melanogaster. Proc Natl Acad Sci USA 2004, I 0 I:6764-6769.

17. Strauss A, Bitsch F, Fendrich G, Graff P, Knecht R, Meyhack B, Jahnke $W$ : Efficient uniform isotope labeling of Abl kinase expressed in Baculovirus-infected insect cells. J Biomol NMR 2005, 3I:343-349.

18. Silva FJ, Bel Y, Botella LM, Cotton RG, Ferre J: Immunological detection of phenylalanine hydroxylase protein in Drosophila melanogaster. Biochem J 1992, 287:85-89.

19. Bel $\mathrm{Y}$, Wiesner $\mathrm{P}$, Kayser $\mathrm{H}$ : Candidate target mechanisms of the growth inhibitor cyromazine: studies of phenylalanine hydroxylase, puparial amino acids, and dihydrofolate reductase in dipteran insects. Arch Insect Biochem Physiol 2000, 45:69-78.

20. Ruiz-Vázques P, Silva F): Aberrant splicing of the Drosophila melanogaster phenylalanine hydroxylase pre-mRNA caused by the insertion of a BI04/roo transposable element in the Henna locus. Insect Biochem Mol Biol 1999, 29:3। I-318.

21. Drews M, Doverskog M, Ohman L, Chapman BE, Jacobsson U, Kuche PW, Haggstrom L: Pathways of glutamine metabolism in Spodoptera frugiperda (Sf9) insect cells: evidence for the presence of the nitrogen assimilation system, and a metabolic switch by 'H/15 N NMR. J Biotechnol 2000, 78:23-27.

22. Bligh EG, Dyer W]: A rapid method of total lipid extraction and purification. Can J Biochem Physiol 1959, 37:911-917.

23. Eisenreich $W$, Schwarzkopf $B$, Bacher A: Biosynthesis of nucleotids, flavins, and deazaflavins in Methanobacterium thermoautotrophicum. J Biol Chem 199I, 226:9622-963I.

24. Eisenreich W, Bacher A: Elucidation of biosynthetic pathways by retrodictive/predictive comparison of isotopomer patterns determined by NMR spectroscopy. Volume 22. Edited by: Setlow JK. Genetic Engineering, Principles and Methods. Kluwer Academic/Plenum Publisher, New York; 2000:121-153.
Publish with Bio Med Central and every scientist can read your work free of charge

"BioMed Central will be the most significant development for disseminating the results of biomedical research in our lifetime. "

Sir Paul Nurse, Cancer Research UK

Your research papers will be:

- available free of charge to the entire biomedical community

- peer reviewed and published immediately upon acceptance

- cited in PubMed and archived on PubMed Central

- yours - you keep the copyright
BioMedcentral 